\title{
Serial order anticipation learning in rats: Memory for multiple hedonic events and their order
}

\author{
E. J. CAPALDI and DONNA R. VERRY \\ Purdue University, West Lafayette, Indiana 47907
}

\begin{abstract}
Many characteristics of a series of discrete independent hedonic events may be remembered by rats in terms of, for example, how many events were rewarded and how many were nonrewarded. Such memory for multiple hedonic events, which has been shown to be a potent factor controlling instrumental responding, was examined here in five investigations employing serial anticipation learning in a runway. It was found that the ability of rats to remember the hedonic events reward and nonreward is highly developed, accurate, and quite resistant to forgetting and interference. Rats not only remembered a rewarded event and a nonrewarded event, but they also remembered the order in which the two events occurred. Rats remembered how many nonrewarded events there had been accurately enough to suggest that they were using some form of a counting mechanism. Rats exhibited little forgetting of eight prior discrete hedonic events, one rewarded followed by seven nonrewarded, even when these occurred over an interval of $20 \mathrm{~min}$ and involved considerable potential interference. In the serial learning situation employed here, marked primacy effects were obtained, earlier nonrewarded trials in a series being better anticipated than later ones. The primacy effect was found to depend upon the type of series employed. By assuming that stimulus generalizations occur between the multiple hedonic events remembered by rats, all anticipatory learning obtained here could be explained in considerable detail.
\end{abstract}

Investigations of partial reinforcement indicate that rats remember having been rewarded and can remember the number of nonrewarded trials they have received (e.g., Capaldi, 1964, 1966, 1967, 1979). These and other characteristics of a series of discrete hedonic events that rats may. remember were investigated here employing serial order anticipation learning. Events occurring in series, represented as A-B-CD. . . . including verbal events (memorizing a list of words), motor events (learning tennis), spatial events (learning a maze), and, as here, series of rewarded and nonrewarded trials in a runway. Memory of hedonic events has been shown to exercise considerable control over instrumental responding, particularly in reward schedule and discrimination learning situations (see, e.8., Capaldi, 1964; Capaldi, Berg, \& Morris, 1975; Capaldi, Verry, \& Davidson, 1980; Haggbloom \& Tillman, 1980). Thus, a better understanding of hedonic-event memory should lead to a better understanding of instrumental learning generally. In addition, the investigations reported here are relevant to a variety of more specific contemporary concerns: the basis of serial order learning in animals (see, e.g.,. Capaldi et al., 1980; Hulse, 1978), the role of interference in long-delay learning in animals (see, e.g.,

This research was supported by NSF Grant BNS 80-01171 to E. J. Capaldi.
Lett, 1979), and the ability of animals to remember two or more events and their order of occurrence (e.g., Capaldi, 1964; Devine, Burke, \& Rohack, 1979; Shimp, 1976).

In the series employed here, event $B$ could be anticipated by remembering event $\mathbf{A}$. However, event $C$ could not be anticipated by remembering either event $\mathbf{A}$ alone, a remote event, or event $B$ alone, an adjacent event, but required that both events $A$ and $B$ be remembered. In the present series, then, the memory of A signaled B, the memories of $A+B$ signaled $C$, the memories of $A+B+C$ signaled $D$, and so on. It is possible that eventually when the rat received the first event of the series, A, it was able to remember the whole series, B, C, D, and so on. In order to construct series which demonstrated memory for all previous events in the series, two unusual experimental procedures were used.

First, rats were required to learn not a single list of events, as is typical, but two different lists of events simultaneously. This "two-series" procedure in combination with the second procedure employed here did two things: it made correct anticipation of any given event dependent upon remembering all prior events in the series, and it rendered a variety of alternative sources of stimulus control irrelevant, a matter that will be examined in detail in the general discussion section.

The second noteworthy procedure employed here, 
which has been utilized in some animal learning investigations (e.g., Bloom \& Capaldi, 1961; Hunter, 1920) and in some human learning investigations (e.g., Restle \& Brown, 1970), may be called branching. A series branches when a given event is followed by different events depending upon prior events; for example, $\mathrm{C}$ is followed by either $\mathrm{D}$ or $\mathrm{E}$, depending upon whether the preceding event was A or B. The branching procedure in combination with the twoseries procedure demanded, as we shall see, that rats remember all prior events in the series in order for correct anticipation to occur.

\section{EXPERIMENT 1}

Two series of three trials each were employed in Experiment 1. In one, Trial 3 was always rewarded, while in the other, Trial 3 was always nonrewarded. In the terminal rewarded series, symbolized as 0-0-20, two successive 0 -pellet, or nonrewarded, trials were always followed by a 20 -pellet (45-mg pellets) rewarded trial. In the terminal nonrewarded series, symbolized as 20-0-0, a 20-pellet trial was always followed by two successive 0-pellet trials.

In Experiment 1, the 0-0-20 series and the 20-0-0 series occurred twice each day. Once the first trial of a series was presented, all succeeding trials were, in principle, predictable. However, the two series were presented each day such that the first trial was unpredictable. Thus, the first trial of a series, which was unpredictable, will always be viewed differently in the present analysis from the remaining trials of the series, which are predictable from prior trial outcomes.

Of the four predictable events in the combined 0-0-20 and 20-0-0 series, three follow branches, Trials 2 and 3 of the $0-0-20$ series and Trial 3 of the 20-0-0 series, and one event does not follow a branch, namely, Trial 2 of the 20-0-0 series.

\section{Method}

Subjects. The subjects were four male albino rats about 90 days old at the start of the experiment, purchased from the Holtzman Co., Madison, Wisconsin. The rats were housed individually with free access to water.

Apparatus. A straight alley runway, painted a flat gray throughout and measuring $208.4 \mathrm{~cm}$ in length, $10.2 \mathrm{~cm}$ in width, and $22.9 \mathrm{~cm}$ in height, was used. The alley had a hinged $1.3-\mathrm{cm}$ hardware cloth top. The initial $20.3 \mathrm{~cm}$ of the alley was closed off by an aluminum guillotine door to form the startbox. The startbox and goalbox guillotine doors were raised manually $3 \mathrm{sec}$ after the subject had been placed in the alley. Raising the startbox guillotine door automatically started an electronic clock (accurate to $.01 \mathrm{sec}$ ). Interruption of the first photocell $5.08 \mathrm{~cm}$ from the startbox door stopped the first clock (start time) and activated the second clock. Interruption of the second photocell, $133.35 \mathrm{~cm}$ beyond the first photocell, stopped the second clock (run time) and activated the third clock. Interruption of the third photocell, located $39.37 \mathrm{~cm}$ from the second photocell and $6.4 \mathrm{~cm}$ in front of the wooden food cup $(5.1 \times 10.2 \times 3.8 \mathrm{~cm})$, stopped the third clock (goal time). On nonrewarded trials, a fourth clock was activated by interrup- tion of the third photocell to time the 30-sec nonreward confinement duration. To prevent retracing, an aluminum guillotine door in the goal section was lowered following interruption of the third photocell.

Procedure. Pretraining and food deprivation began 10 days after the rats arrived at the laboratory and 12 days prior to the start of experimental training. Throughout the experiment, deprivation consisted of providing the rat with $13 \mathrm{~g}$ of Lab Blox each day about $15 \mathrm{~min}$ after the rat was returned to the home cage. All food provided in the form of Noyes pellets was subtracted from the daily ration. On Days 1-9 of pretraining, the rat was removed from the home cage and handled for about $1 \mathrm{~min}$. On Days 10-12, the rats received $20.045-\mathrm{g}$ Noyes food pellets in the home cage following handling and prior to the daily ration. On Days 11 and 12 of pretraining, each rat was placed individually for $1 \mathrm{~min}$ in the unbaited runway with all equipment turned on and the doors up.

In experimental training, which lasted for 28 days, the rats received two kinds of trial series, twice each day, in an ABBA order on odd days and a BAAB order on even days. One of these series, the terminal rewarded series, consisted of two consecutive nonrewarded trials followed by a 20-pellet rewarded trial, which may be represented as $0-0-20$. The other, the terminal nonrewarded series, consisted of a 20-pellet rewarded trial followed by two consecutive 0-pellet trials, which may be represented as 20-0-0. Each rat was run individually and received all three trials of a series before the next rat was run. On 0-pellet trials, the rat was confined to the goalbox for $30 \mathrm{sec}$, and on 20-pellet trials, the rat was removed immediately after having eaten the last pellet, a process which required about $30 \mathrm{sec}$ later in training and about $60 \mathrm{sec}$ earlier in training. The interval between trials, the intertrial or retention interval, was about $25-30 \mathrm{sec}$. The interval between series presentations, the interseries interval, was about 20-25 min.

The subjects were brought into the experimental room from the colony room in holding cages, where they spent the intertrial and interseries intervals. The holding cages were in one corner of the approximately $4 \times 2 \mathrm{~m}$ experimental room, with the goalbox of the runway in the diagonally opposite corner. At that distance, masking noise from a constantly operating ceiling fan and a method of silently baiting the goal cup with pellets from small cloth-lined paper cups precluded the possibility that noises would indicate whether a rewarded or a nonrewarded trial was about to occur. During the intertrial interval, the experimenter recorded the times from the three clocks located near the goalbox. The rats were allowed a maximum of $60 \mathrm{sec}$ per alley section. If the rat failed to traverse the alley in the allotted time, it was gently placed in the goalbox with its scheduled reward or nonreward. After the last rat was run, all rats were returned to the colony room and home cage.

Anticipatory responding was evaluated on a within-series basis (slower running on the 0-pellet than on a 20-pellet trial of a given series) and on a between-series basis (slower running on the 0 pellet trial of one series than on the 20-pellet trial of the other series). In all of the experiments reported here, anticipatory responding was unaffected by alley section. Thus, only total speed is reported. A separate analysis of variance was performed on each training block, and the size of the training block used in each experiment is clearly identified. Each block employed as factors series, trials in each series, days in each block, and repetitions of each series on each day. The major result of this analysis is the trials $\times$ series interaction. When the trials $\times$ series interaction was significant, it indicated that the two series affected responding differently over trials, allowing the subsequent use of Newman-Keuls posttests to evaluate anticipatory responding on a within-series and a between-series basis.

\section{Results}

Figure 1 shows total speeds in blocks of 2 days on each of the three trials of each of the two series, $0-0-20$ 


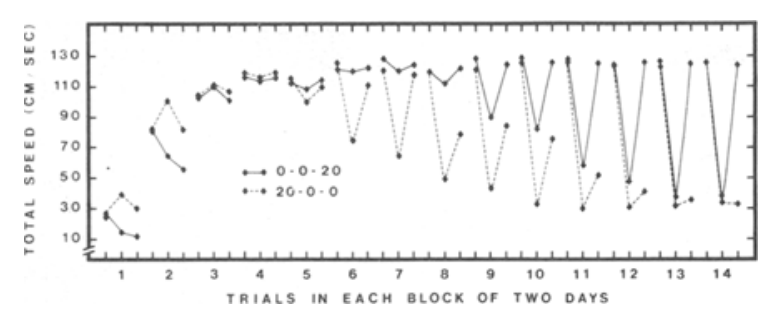

Figure 1. Total speed in blocks of 2 days on each of the three trials of each of the series $0-0-20$ and $20-0-0$.

and 20-0-0. The trials $\times$ series interaction first became significant on Block $6[F(2,6)=12.21, p<.01]$ and was significant on each block thereafter at the .01 level or better. Newman-Keuls posttests applied to each block from Block 6 on indicated that anticipatory responding in Experiment 1 may best be understood by considering the last three blocks of trials, Blocks 12,13, and 14, separately from Blocks 6-11. This is because by Blocks 12,13 , and 14 anticipatory responding became more or less stable, whereas on Blocks 6-11 it was in the process of developing in a characteristic manner, as described below.

Figure 1 shows that, on Blocks 12,13, and 14, essentially two kinds of speed scores were obtained, fast running on three trials, each of the 20-pellet trials and Trial 1 of the $0-0-20$ series, and slow running on the remaining three 0 -pellet trials. Thus, on Blocks 12,13 , and 14 , anticipatory responding occurred on all 0 -pellet trials except Trial 1 of the $0-0-20$ series. Posttests indicated that differences among the three fast running trials were not significant, and that differences among the three slow running trials were not significant, but each of the fast running trials differed significantly from each of the slow running trials (ps $<.01)$.

The three trials that produced fast running failed to differ on Blocks 6-11 as they had in Blocks 12-14. However, on the remaining three 0-pellet trials, anticipatory responding developed, as was indicated, in a characteristic way over Blocks 6-11. Essentially, Trial 2 of the 20-0-0 series was anticipated sooner in training than either Trial 3 of that series or Trial 2 of the $0-0-20$ series, these latter two trials failing to differ on Blocks 6-11 as they had on Blocks 12-14. Statistical support for earlier and better anticipation of Trial 2 of the $20-0-0$ series is as follows. First, on Blocks 6-8, Trial 2 of the $20-0-0$ series was the only 0 -pellet trial anticipated, that trial differing significantly from every other trial in both series (ps $<.01$ ), with no other difference being significant. Moreover, while anticipatory responding on Blocks 9-11 occurred on Trial 2 of the $0-0-20$ series and Trial 3 of the 20-0-0 series ( $p s<.05$ or better), running on those trials was not as slow as it was on Trial 2 of the
20-0-0 series (ps $<.05$ ). By Blocks $12-14$, running on all three of those 0 -pellet trials had become equally slow.

Differential anticipation of items on the basis of their position in the series is common in serial learning tasks (see, e.g., Crowder, 1976). Figure 1 shows a definite primacy effect, 0 -pellets being anticipated much earlier in training on Trial 2 than on Trial 3 of the 20-0-0 series. This effect can be called the nonrewarded-trial primacy effect. Figure 1 also shows that Trial 2 was anticipated much earlier in training in the 20-0-0 series than in the $0-0-20$ series. This may be called the series-dependent nonrewarded-trial primacy effect, anticipation of 0 pellets being affected by type of series as well as position in the series. The nonrewarded-trial primacy effect and the seriesdependent nonrewarded-trial primacy effect together define the nonrewarded-trial serial position effect.

\section{Discussion}

These rats demonstrated, unmistakably, that they were able to master branching series by running more slowly on the two 0-pellet trials that followed a branch (Trial 2 of the $0-0-20$ series and Trial 3 of the 20-0-0 series) than on the rewarded trial that followed a branch (Trial 3 of the 0-0-20 series). They also ran slowly on Trial 2 of the 20-0-0 series, but that trial was not a branching trial, since it followed a 20-pellet trial. Schlosberg and Katz (1943) suggested that rats can learn branching series of the double-alternation type more easily, and perhaps only, when the events of the series are presented rapidly and without intervening activity. This clearly does not hold for the branching series employed here, in which events were separated by a $25-30-\mathrm{sec}$ retention interval and the events themselves were not presented rapidly. The confinement duration was $30 \mathrm{sec}$ on 0-pellet trials and 30-60 sec on 20-pellet trials.

\section{EXPERIMENTS 2 AND 3}

It should be clear from prior research on hedonic memory how Trials 2 and 3 of the $0-0-20$ series and Trial 2 of the $20-0-0$ series were anticipated. What is not clear is how Trial 3 of the 20-0-0 series was anticipated. Experiments 2 and 3, which were conducted separately, are reported together because both were concerned with this problem. In general terms, the problem is this: Does retroactive interference occur such that a nonrewarded event produces forgetting of a prior reward event?

The series employed in Experiment 1 were based upon information about hedonic memory obtained from investigations concerned with such problems as the effects of various reward schedules on resistance to extinction (see, e.g., Capaldi, 1964, 1966, 1967, 1979; Capaldi et al., 1980). Reward schedule findings 
indicate that rats can remember rewarded events, and would suggest that it was the memory of the 20 -pellet reward which signaled 0 pellets on Trial 2 of the 20-0-0 series. Reward schedule data also indicate that rats can remember not merely one, but two or more nonrewarded events, and so would suggest that it was the memory of a single 0 -pellet event which signaled 0 pellets on Trial 2 of the $0-0-20$ series, and it was the memory of two 0 -pellet events which signaled 20 pellets on Trial 3 of the $0-0-20$ series. However, reward schedule data fail to indicate unambiguously whether a nonrewarded event produces forgetting of a rewarded event. Thus, there are two possibilities as to how Trial 3 of the 20-0-0 series was anticipated.

One possibility, based on the assumption that a nonrewarded event produces forgetting of a prior rewarded event, is that Trial 3 of the $20-0-0$ series was signaled by the memory of the 0 -pellet event that occurred on Trial 2. If this view is correct, branching behavior in Experiment 1 could have been based on a discrimination between one and two nonrewarded events. According to this view, the rats learned that a single 0 -pellet event was always followed by 0 -pellets (Trial 2 of the $0-0-20$ series and Trial 3 of the 20-0-0 series), while two 0 -pellet events were always followed by 20 pellets (Trial 3 of the $0-0-20$ series).

A second possibility, based on the assumption that a nonrewarded event does not produce forgetting of a rewarded event, is that Trial 3 of the $20-0-0$ series was signaled by a multiple memory, that of the 20 pellet event from Trial 1 and the 0-pellet event from Trial 2. Experiments 2 and 3 attempted to extend available information about hedonic memory by determining whether rats could remember a rewarded event and a nonrewarded event in succession. In Experiments 2 and 3, each series contained only one 0 -pellet trial, and branches followed this trial. That is, in Experiments 2 and 3, unlike Experiment 1, branching behavior could not be based upon a discrimination between one and two 0-pellet events. Rather, to show branching behavior in Experiments 2 and 3, the rat had to remember a rewarded event along with a nonrewarded event.

In Experiment 2, rats received the series 1-0-20 and 20-0-0. Branching behavior in Experiment 2 would be demonstrated by running that was faster on Trial 3 of the 1-0-20 series than on Trial 3 of the 20-0-0 series, a branch that follows a single nonrewarded trial in both series.

The series 5-0-20 and 20-0-0 were used in Experiment 3. The 5-pellet reward cannot reasonably be considered to be highly similar to 0-pellets (as can a 1-pellet reward), and 5 pellets may be discriminable enough from 20 pellets to allow branching to occur, which would consist of faster running on Trial 3 of the 5-0-20 series than on Trial 3 of the
20-0-0 series, a branch which follows 0 pellets in both series.

\section{Method}

Subjects. Experiments 2 and 3 were run separately. Each contained four rats, similar to those of Experiment 1, which were housed individually with free access to water.

Apparatus. The apparatus was the same as that used in Experiment 1.

Procedure. Pretraining and deprivation in Experiments 2 and 3 were the same as in Experiment 1. Experimental training in Experiments 2 and 3 was exactly as in Experiment 1 except for the following differences. In Experiment 2, the two series employed were $1-0-20$ and $20-0-0$ and there were 27 days of training. On 1and 20-pellet trials, the rats were removed from the goalbox immediately after having eaten the pellets and confinement on nonrewarded trials was $30 \mathrm{sec}$, as before. In Experiment 3, the two series were $5-0-20$ and $20-0-0$ and there were 28 days of training.

\section{Results}

The results obtained in Experiment 2 are given in Figure 2, which shows total speed in blocks of 3 days on each of the three trials of each of the two series 1-0-20 and 20-0-0. The results obtained in Experiment 2 are essentially similar to those obtained in Experiment 1. The trials $\times$ series interaction was significant by Block $5[\mathrm{~F}(2,6)=6.25, \mathrm{p}<.05]$ and remained significant on each subsequent block. Differences among Trials 1 and 3 of the 1-0-20 series and Trial 1 of the 20-0-0 series were not significant at any point in training. Newman-Keuls tests indicated that there was a nonrewarded-trial primacy effect under the 20-0-0 series. First, running was slower on Trial 2 than on Trial 3 of the 20-0-0 series on each of Blocks $5-9$ (ps $<.05$ or better). Anticipatory responding on Trial 2 of the 20-0-0 series also first appeared on Block 5 (ps $<.01$ ), while it did not appear on Trial 3 of the 20-0-0 series until Block 7 (ps $<.05$ or better). Newman-Keuls tests also indicated that there was a series-dependent nonrewarded-trial primacy effect. On each of Blocks 5-7, running was significantly slower on Trial 2 of the 20-0-0 series than on Trial 2 of the $1-0-20$ series (ps $<.05$ ).

Figure 3 shows total speed in blocks of 2 days on each of the three trials of the 5-0-20 and 20-0-0 series.

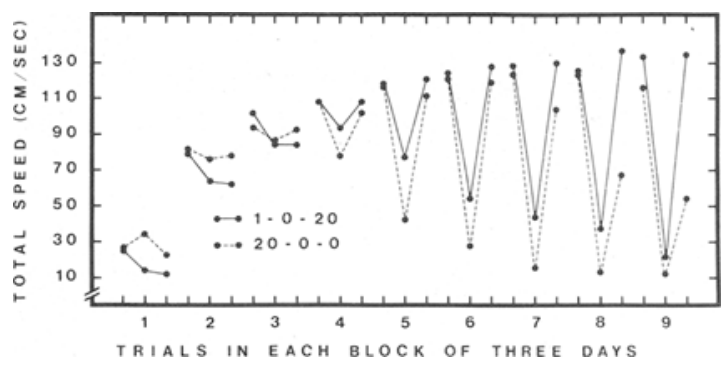

Figure 2. Total speed in blocks of 3 days on each of the three trials of each of the series 1-0-20 and 20-0-0. 


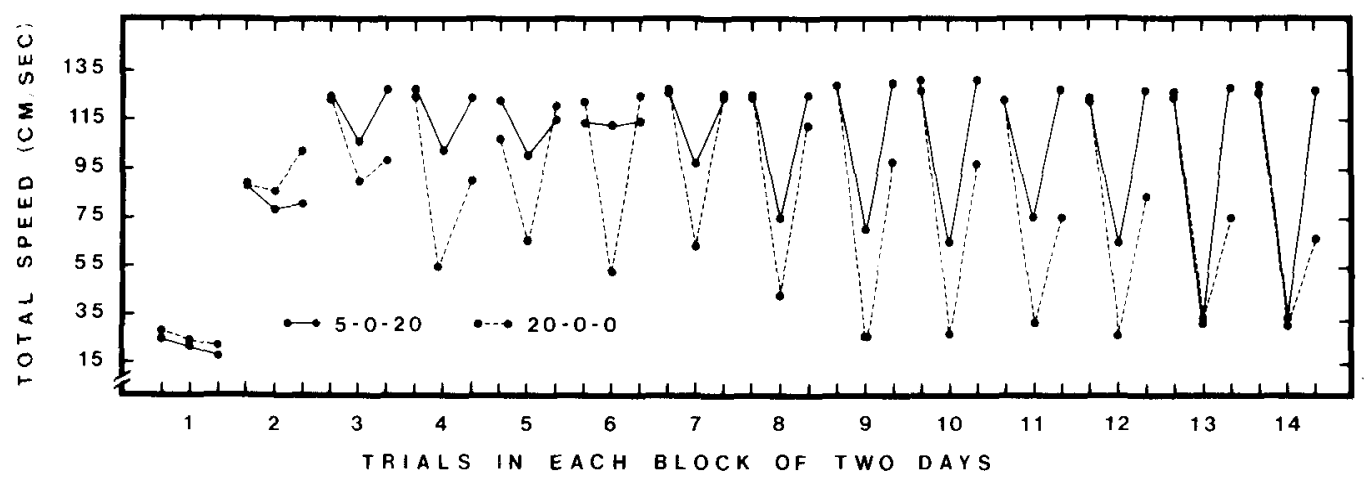

Figure 3. Total speed in blocks of 2 days on each of the three trials of each of the series 5-0-20 and 20-0-0.

The results obtained in Experiment 3 are clearly similar to previous findings reported here. First, branching occurred, running soon becoming slower on Trial 3 of the 20-0-0 series than on Trial 3 of the 5-0-20 series. Also, a nonrewarded-trial primacy effect was shown by the fact that Trial 2 of the 20-0-0 series was anticipated earlier in training than Trial 3 of that series. Finally, a series-dependent nonrewardedtrial primacy effect was obtained, with Trial 2 of the 20-0-0 series being anticipated sooner in training than Trial 2 of the 5-0-20 series.

The trials $\times$ series interaction first became significant on Block $4[F(2,6)=7.75, p<.05]$ and was significant on each block thereafter at the .05 level or better. Newman-Keuls posttests indicated that on each of Blocks 4-12, Trial 2 of the 20-0-0 series differed significantly from every other trial in both series at the .05 level or better, and that on Blocks 13 and 14, Trial 2 of the 20-0-0 series differed from every other trial in both series at the .05 level or better, except for Trial 2 of the 5-0-20 series. Trial 3 of the 20-0-0 series differed from Trial 2 of the 5-0-20 series at the .05 level or better on each of Blocks 9-14. Anticipation of Trial 2 of the 5-0-20 series occurred on each of Blocks 8-14 (ps $<.05$ or better), and anticipation of Trial 3 of the 20-0-0 series occurred on each of the Blocks 9-14 (ps $<.05$ or better).

\section{Discussion}

The branching findings obtained in Experiment 1 are consistent with the view that rats are capable of learning that a single nonrewarded event is followed by a nonrewarded event while two nonrewarded events are followed by a rewarded event. In Experiments 2 and 3 , the branch in the series followed a single nonrewarded trial, and appropriate anticipation was still found. Thus, Experiments 2 and 3 indicate that branching in rats can be sustained by information other than the number of prior nonrewarded trials in the series. Apparently rats can remember a rewarded event followed by a nonrewarded event.
In Experiment 3, under the 5-0-20 series, for example, the memory of a 5-pellet reward became a signal for 0 pellets, and so running was slow, while the multiple memory of a 5-pellet and a 0-pellet reward became a signal for 20 -pellets, and so running was fast.

In Experiments 2 and 3, anticipation of 0 pellets occurred sooner in training on Trial 2 than on Trial 3 of the 20-0-0 series, a nonrewarded-trial primacy effect. Also, in both experiments anticipation of 0 pellets occurred sooner on Trial 2 of the terminal nonrewarded series than on Trial 2 of the terminal rewarded series, a series-dependent nonrewarded-trial primacy effect. In Experiments 2 and 3, as in Experiment 1 , anticipation of the smaller reward on Trial 1 of the series did not occur.

\section{EXPERIMENT 4}

Experiments 2 and 3 indicated that rats are able to remember a rewarded event followed by a nonrewarded event. Experiment 4 was undertaken to obtain additional evidence on this point on the issue of whether rats can remember a nonrewarded event followed by a rewarded event. And, most importantly perhaps, Experiment 4 was undertaken to determine if rats could remember the order in which a rewarded event and a nonrewarded event occurred. That is, Experiment 4 was designed to determine if rats could discriminate between and remember a rewarded event followed by a nonrewarded event vs. a nonrewarded event followed by a rewarded event.

Experiment 4 employed the series $0-20-20$ and 20-0-0. In these series, the same two events occur on Trials 1 and 2, 0 pellets and 20 pellets, but in opposite order. Experiment 4 was so designed that if running were fast on Trials 2 and 3 of the 0-20-20 series and slow on Trials 2 and 3 of the 20-0-0 series, it could be concluded that rats were capable of remembering the order of occurrence of two hedonic events, 
one rewarded and the other nonrewarded. Consider why. Fast running on Trial 3 of the $0-20-20$ series could not be attributed to the memory of the immediately prior hedonic event alone, 20 pellets, because that memory produced slow running on Trial 2 of the 20-0-0 series. And slow running on Trial 3 of the 20-0-0 series could not be attributed to the memory of the immediately prior hedonic event alone, 0 pellets, because that memory produced fast running on Trial 2 of the $0-20-20$ series. Thus, in order to run fast on Trial 3 of the $0-20-20$ series and slowly on Trial 3 of the 20-0-0 series, both prior hedonic events in both series would have to be remembered. And since these are the same events, 0 pellets and 20 pellets, their order must be remembered as well. Thus, in Experiment 4, fast running on Trials 2 and 3 of the $0-20-20$ series and slow running on Trials 2 and 3 of the 20-0-0 series would indicate that the multiple memory of a 0-pellet event followed by a 20-pellet event was the signal for 20 pellets on Trial 3 of the 0-20-20 series, while the multiple memory of a 20 pellet event followed by a 0 -pellet event was the signal for 0 pellets on Trial 3 of the 20-0-0 series.

Another difference between Experiment 4 and Experiments 1,2 , and 3 is worthy of mention. In Experiments 1, 2, and 3, all branches followed nonrewarded trials. In Experiment 4 , a branch followed rewarded trials as well as nonrewarded trials. The branch following reward in Experiment 4 involved comparing Trial 3 of the 0-20-20 series with Trial 2 of the 20-0-0 series. And the branch following nonreward involved comparing Trial 2 of the $0-20-20$ series with Trial 3 of the $20-0-0$ series.

\section{Method}

The subjects were six rats similar to those of Experiment 1. The apparatus and procedures were the same as those used in Experiment 1 , except that the two series were $0-20-20$ and 20-0-0. The interseries interval was about $20 \mathrm{~min}$, and there were 38 days of experimental training.

\section{Results}

Figure 4 shows total speeds, in blocks of 2 days, in each of the three trials of each of the two series, $0-20-20$ and 20-0-0. Anticipatory responding eventually developed on Trials 2 and 3 of the 20-0-0 series, but re- quired much more training than in the previous investigations. There was also little tendency toward a nonrewarded-trial primacy effect in Experiment 4; anticipatory responding developed about as rapidly on Trial 3 as on Trial 2 of the $20-0-0$ series. The trials $x$ series interaction first became significant on Block $14[F(2,10)=6.64, p<.01]$ and remained significant at the .01 level or better on all subsequent blocks. Newman-Keuls posttests indicated that on each of Blocks 14-19, Trials 2 and 3 of the 20-0-0 series, which did not differ from each other, differed from every other trial in the two series (ps $<.01$ or better). No other differences were significant.

\section{Discussion}

Consistent with the previous findings reported here, rats showed branching behavior following nonrewarded trials by running faster on Trial 2 of the 0-20-20 series than on Trial 3 of the 20-0-0 series. Moreover, by running faster on Trial 3 of the 0-20-20 series than on Trial 2 of the 20-0-0 series, rats showed that they were capable of branching behavior following a rewarded trial, and that a rewarded event does not produce forgetting of a nonrewarded event. Most importantly, by running faster on Trial 3 of the 0-20-20 series than on Trial 3 of the 20-0-0 series, rats showed that they are capable of remembering the order in which a 0-pellet event and a 20-pellet event occurred.

Performance under the 20-0-0 series in the earlier experiment differed from that in Experiment 4. In Experiments 1, 2, and 3, unlike Experiment 4, a nonrewarded trial primacy effect occurred in connection with the 20-0-0 series, anticipation of 0 pellets in that series occurring earlier on Trial 2 than on Trial 3. In Experiment 4, however, 0 pellets was anticipated about as readily on Trial 3 as on Trial 2 of the 20-0-0 series. Undoubtedly, in Experiment 4, performance under the 20-0-0 series was affected by the second series employed, the 0-20-20 series, which may be called an intervening rewarded series. More generally, we may suppose that under the two-series procedure, performance under one series will depend upon the other series employed.

In Experiment 4, running was as rapid throughout

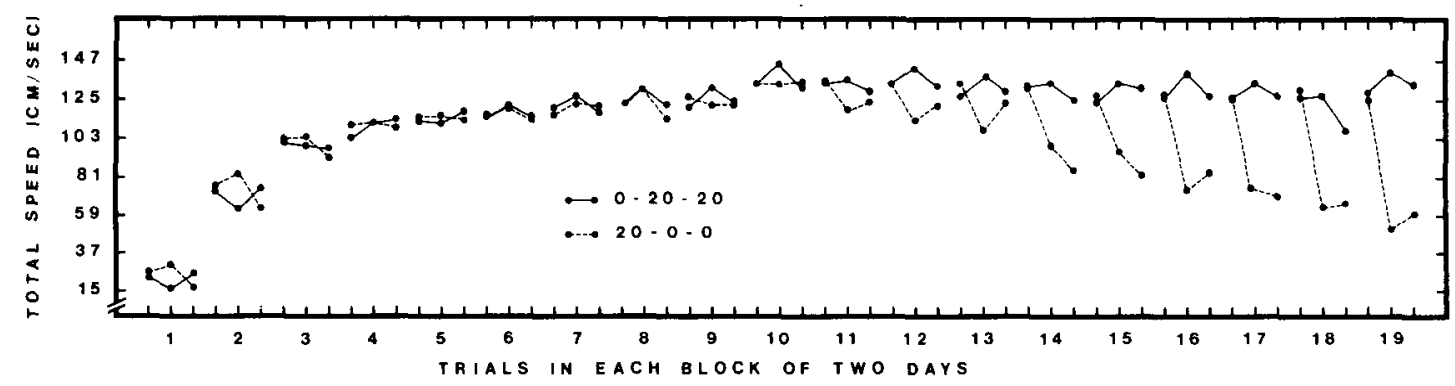

Figure 4. Total speed in blocks of 3 days on each of the three trials of each of the series 0-20-20 and 20-0-0. 
training on Trial 1 of the $0-20-20$ series as on Trial 1 of the 20-0-0 series, indicating that rats were unable to anticipate Trial 1 hedonic events.

\section{EXPERIMENT 5}

Experiment 5 was conducted in two phases. In Phase 1, rats received the series $0-0-0-0-20$ and $20-0$ $0-0-0$. One reason for employing these series was the more complete information they could provide concerning the nonrewarded-trial serial-position effect. Because of the relatively short three-trial series employed, information about that effect so far reported here is deficient in two respects. The first deficiency is that all information obtained here about the nonrewarded-trial primacy effect comes from the terminal nonrewarded series $20-0-0$, because the terminal rewarded series 0-0-20, 1-0-20, and 5-0-20 employed in Experiments 1, 2, and 3, respectively, contain only one nonrewarded trial that could be anticipated. Whether a nonrewarded trial primacy effect will also occur in connection with a terminal rewarded series could be determined in Experiment 5 because the series $0-0-0-0-20$ contains three 0 -pellet trials which can be anticipated. A second deficiency is that, with the three-trial series employed in Experiments 1, 2, and 3 , the series-dependent nonrewarded-trial primacy effect could be manifested only on the second trial of the two series. However, by employing the $0-0-0-0-20$ and $20-0-0-0-0$ series, the serial-dependent nonrewarded-trial primacy effect could be observed in connection with the three trials in the middle of the two series. It should be mentioned, too, that the nonrewarded-trial primacy effect could be observed in connection with four trials with the $20-0-0-0-0$ series.

Experiment 5 had a second major purpose. The branch that occurs on Trial 5 of the $0-0-0-0-20$ and 20-0-0-0-0 series is differentially signaled by hedonic events which occur four trials earlier in each of the two series. Are rats capable of utilizing information about branches provided as many as four trials earlier? Previously in this report, the earliest information provided was two trials prior to a branch, as, for example, in the 0-0-20 and 20-0-0 series of Experiment 1. In Experiment 5, Phase 2 was initiated following the development of robust branching on all trials in Phase 1. Phase 2 was initiated in an attempt to determine if rats could utilize information about a branch presented more than four trials earlier, such information ultimately being provided in one series as many as eight trials earlier. This was accomplished as follows. In Phase 2, training under the $0-0-0-0-20$ series continued as in Phase 1 . However, on the first day of Phase 2, an additional 0-pellet trial was added to the 20-0-0-0-0 series, making it a 20-0-0-0-0-0 series. Two days later, still another 0-pellet trial was added, and this general procedure was followed until, by the end of Phase 2, the terminal nonrewarded series consisted of the nine trials $20-0-0-0-0-0-0-0-0$. The time elapsing between the termination of the 20 pellet trial and the beginning of the last 0-pellet trial depended in part upon how fast the rats on the intervening seven 0 -pellet trials. Interestingly, about $20 \mathrm{~min}$ usually elapsed between these two events, or about the same interval as had elapsed between series presentations in Phase 1.

\section{Method}

The subjects were four rats similar to those of Experiment 1. The apparatus was the same as that used in Experiment 1, as was the procedure, except for the following differences. In Phase 1, which lasted 36 days, the four rats received the series $0-0-0-0-20$ and 20-0-0-0-0. In Phase 2, which began on Day 37 and lasted 16 days, training under the $0-0-0-0-20$ series was as in Phase 1 , except that 0-pellet trials were added to the 20-0-0-0-0 series, one additional on Days 1 and 2, two additional on Days 3 and 4, three additional on Days 5-10, and four additional on Days 11-16. Thus, on Days 11-16, the terminal nonrewarded series consisted of nine trials. At this point, about 20 min had elapsed between the termination of the 20-pellet trial on Trial 1 and the initiation of the 0-pellet trial on Trial 9. This interval was about as long as the interseries interval in Phase 1 and about as long as the interseries interval in Phase 2 under the terminal rewarded series. However, in Phase 2 the interseries interval increased under the terminal nonrewarded series until ultimately it was about $45-60 \mathrm{~min}$.

\section{Results}

Figure 5 shows total speed in Phase 1 in blocks of 3 days on each of the five trials of each of the two series, $0-0-0-0-20$ and $20-0-0-0-0$. The trials $\times$ series inter-

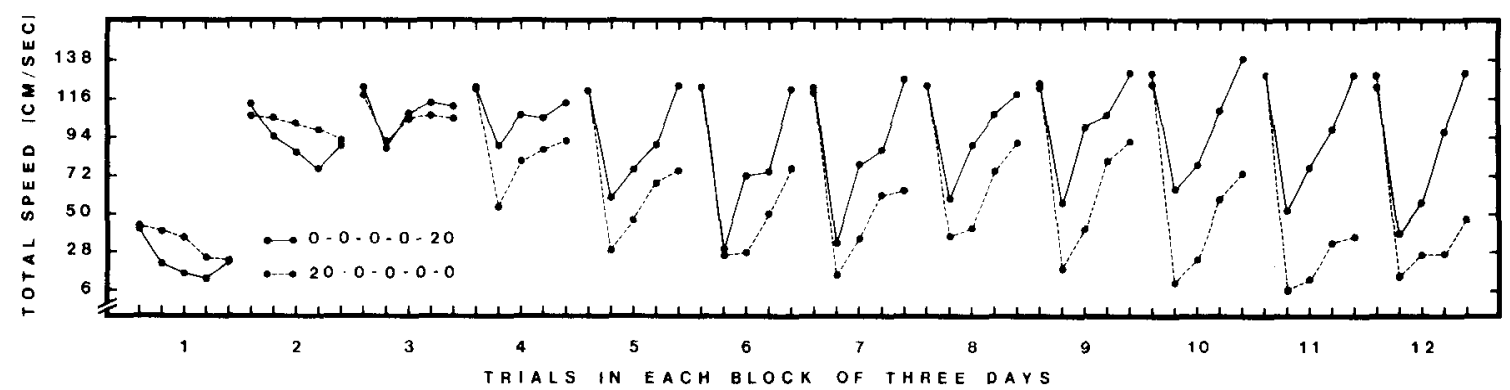

Figure 5. Total speed in blocks of 3 days on each of the five trials of each of the series $0-0-0-0-20$ and $20-0-0-0-0$ in Phase 1. 
action first became significant on Block $6[F(4,12)=$ $4.15, \mathrm{p}<.01]$ and remained significant on each block thereafter (ps $<.01$ or better). Newman-Keuls posttests revealed that, on each block from Block 6 on, anticipatory responding occurred on every 0 -pellet trial of the two series (ps $<.05$ or better) except Trial 1 of the $0-0-0-0-20$ series. On none of the training blocks did speeds on the two 20-pellet trials differ either from each other or from Trial 1 of the $0-0-0-0-20$ series.

Statistical evidence for the series-dependent nonrewarded-trial primacy effect, that is, better anticipation of Trials 2, 3, and 4 of the 20-0-0-0-0 series than of the 0-0-0-0-20 series, first appeared on Block 6 . On Block 6, running was slower on Trials 3 and 4 of the 20-0-0-0-0 series than on Trials 3 and 4 of the 0-0-0-0-20 series (ps $<.05$ or better). And on each of Blocks 8-12, running was slower on Trials 2,3 , and 4 of the 20-0-0-0-0 series than on Trials 2, 3, and 4 of the $0-0-0-0-20$ series (ps $<.05$ or better).

The nonrewarded-trial primacy effect, a difference on Trials 2,3 , and 4 of the $0-0-0-0-20$ series and the 20-0-0-0-0 series that indicates better anticipation of a 0-pellet trial the earlier its position in the series, occurred strongly in both series (see Figure 5). Statistical evidence for the nonrewarded-trial primacy effect occurred as early as Block 6 and had not disappeared completely in either series by Block 12 . On Block 6, running was slower on Trial 2 than on either Trial 3 or Trial 4 (ps $<.01$ ) under the $0-0-0-0-20$ series and slower on Trials 2 and 3 than on either Trial 4 or Trial 5 (ps $<.05$ or better) under the 20-0-0-0-0 series. On Block 12, running was still slower on Trials 2 and 3 than on Trial 4 (ps $<.01$ ) under the $0-0-0-0-20$ series and slower on Trial 2 than on Trial $5(\mathrm{p}<.05)$ under the $20-0-0-0-0$ series. Statistically, a perfect instance of the nonrewarded trial primacy effect would occur if each 0-pellet trial in a series was significantly faster than the immediately previous 0 -pellet trial, excepting, of course, Trial 1 of the $0-0-0-0-20$ series. Such perfect instances occurred statistically in the $0-0-0-0-20$ series on Blocks 8 and 11 (ps $<.05$ or better) and in the 20-0-0$0-0$ series on Block 10 (ps $<.05$ or better).
Figure 6 shows total speed on each of the 16 days of Phase 2 on each of the five trials of the terminal rewarded series, and on each of the 6 to 9 trials provided in the terminal nonrewarded series on a particular day. Three matters shown in Figure 6 are especially noteworthy. First, and most importantly, each newly added 0-pellet trial was anticipated on the day it was introduced, these being Days $1,3,5,11$ of Phase 2, and on each subsequent day thereafter. Second, in the terminal nonrewarded series, the introduction of 0 -pellet trials affected performance only slightly and temporarily. That is, a day or two after the introduction of a 0 -pellet trial there may have been a tendency to speed up somewhat on the later trials of the terminal nonrewarded series, but this tendency quickly disappeared. Finally, while the introduction of 0-pellet trials may have had a slight temporary effect on performance under the terminal nonrewarded series, no discernible effect appears in the terminal rewarded series, in which performance in Phase 2 continued to be as in Phase 1 .

A within analysis of variance was applied to the terminal nonrewarded series on each day of Phase 2. This analysis produced a difference significant at the .001 level or better on each day of Phase 2. On Day 5 of Phase $2, F(7,21)=9.55$, the smallest $F$ value obtained, and on Day 2 of Phase $2, F(5,15)=89.70$, the largest $F$ value obtained. Subsequent NewmanKeuls posttests indicated that on each block, every 0 -pellet trial was anticipated (ps $<.01$ or better). While on some blocks, some 0-pellet trials differed significantly from others, on the last block of trials, Block 16, no 0-pellet trial differed significantly from any other.

A within analysis of variance was applied to the terminal rewarded series on each day of Phase 2. This analysis produced a difference significant at the .01 level or better on each day of Phase 2. On Day 10 of Phase $2, F(4,12)=7.59(p<.01)$, the smallest $F$ value obtained, and on Day 14 of Phase $2, F(4,12)=$ $64.95(p<.001)$, the largest $F$ value obtained. Subsequent Newman-Keuls posttests indicated that on every block, Trials 2,3 , and 4 were anticipated (most ps $<.01$ ) while Trial 1 was not. Furthermore, on

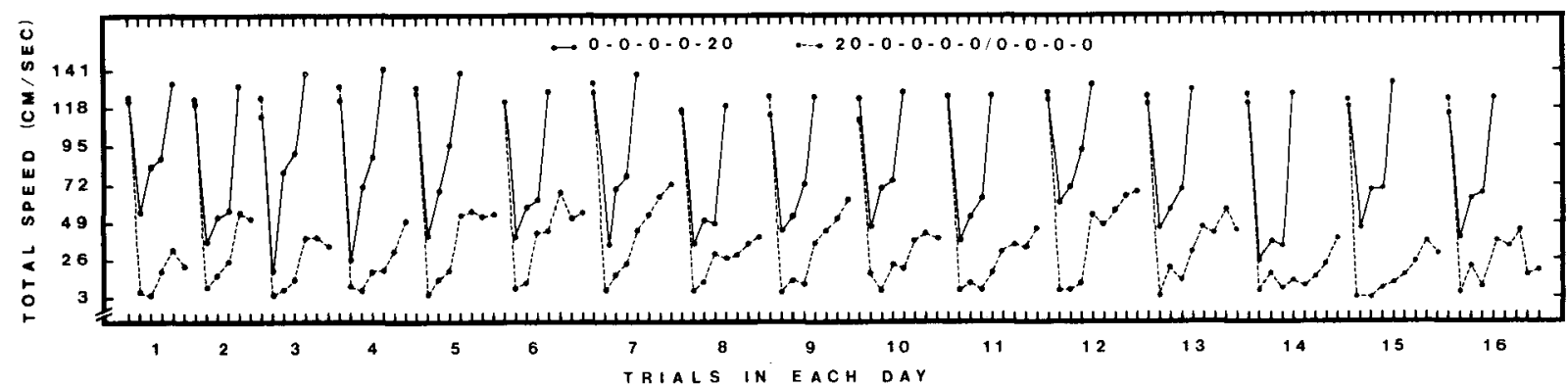

Figure 6. Total speed on each of the 16 days of Phase 2 on each of the 5 trials of the terminal rewarded series and on each of the 6-9 trials of the terminal nonrewarded series that occurred on a particular day. 
most blocks, Trials 2,3 , and 4 did not differ significantly.

\section{Discussion}

In Experiment 5, Group 0-0-0-0-20 ultimately manifested appropriate branching behavior by running faster on the rewarded branching trial of its $0-0-0-0-20$ series than on any of its nonrewarded branching trials in either series. Clearly, in Phase 1, rats utilized hedonic information about branches presented as many as four trials earlier on each of two series.

The results obtained in Phase 1 of Experiment 5 are in complete conformity with the two characteristics of the nonrewarded-trial serial position effect described earlier. First, a series-dependent nonrewarded-trial primacy effect occurred, a nonrewarded trial in a particular position being anticipated sooner in training in the terminal nonrewarded series than in the terminal rewarded series. Indeed, when Phase 1 training was terminated, running to a nonrewarded trial in a given position was faster in the terminal rewarded series than in the terminal nonrewarded series. The second characteristic of the nonrewarded-trial serial-position effect, the nonrewarded-trial primacy effect, defined as the earlier anticipation of nonreward the earlier its position in the series, was also obvious in Phase 1 of Experiment 5 in both series.

By the end of Phase 2, in order to run slowly on the last trial of the terminal nonrewarded series, the rats had to utilize information that was presented eight trials and some $\mathbf{2 0} \mathrm{min}$ or so earlier. Thus, as indicated, by the end of Phase 2 the time elapsing between presentation of the first and last trial of the terminal nonrewarded series was about as long as all interseries intervals in Phase 1 and some of the interseries intervals in Phase 2 . Since running was faster on the first trial of each series than on the last trial of the terminal nonrewarded series, it is clear that the rats' behavior was controlled by events occurring in time rather than by the passage of time itself. It might be hypothesized that the animal instructed itself to remember and forget appropriately based upon its experience in the situation (see, e.g., Honig, 1978; Maki \& Hegvik, 1980). According to this view, as long as trials occurred at a $25-30-\mathrm{sec}$ interval, the rat instructed itself to remember all prior hedonic events in the series, no matter how far removed in time. However, once a relatively long interval had elapsed without a trial, it was no longer useful to remember prior hedonic events, and the rat used this cue as the instruction to forget all prior hedonic events.

Lett (1979) has distinguished between two types of long-delay learning and has explicitly suggested that long-delay learning will not occur under conditions of interference. Lett (1979) distinguished between two forms of long-delay learning, delayed-reward learning, an example of which she employed (e.g., Lett, 1975), and delayed-response learning, an example of which we employed here. In delayed-reward learning, a delay intervenes between the response and reward, and in delayed-response learning, events occurring on a previous trial or trials indicate whether or not a response occurring on a subsequent trial or trials will be rewarded.

In Lett's delayed-reward situation, the rat was rewarded in the startbox after a correct response in a $\mathrm{T}$-maze, following a delay interval. Interference in this situation appeared to be highly deleterious. Thus, Lett (1975) reported that while rats removed immediately from the apparatus learned readily, even with long delays, rats detained in the apparatus for as little as $60 \mathrm{sec}$ following a choice failed to learn, an outcome Lett attributed to interfering associations learned in the apparatus. A similar analysis seemed appropriate to Lett in connection with delayedresponse learning. For example, the single alternation of rewarded and nonrewarded trials, even at retention intervals of $24 \mathrm{~h}$ (Capaldi \& Lynch, 1966; Jobe, Mellgren, Fineberg, Littlejohn, \& Righy, 1977), have eventually produced appropriate responding, that is, faster running on rewarded than on nonrewarded trials. Lett identified the alternation situation as one of low interference because the entire retention interval was spent outside the apparatus.

However, the present delayed-response situation, unlike the single-alternation one, was one that engendered extraordinarily high levels of interference. Interference should occur not only because the animal was repeatedly returned to the apparatus, but also because in Phase 2 of Experiment 5 the animal received two series such that the characteristic events intervening between the first and last trials of the series were identical, that is, 0 -pellet events. In one series, the intervening 0-pellet events were followed by reward, and in the other, by nonreward. Thus, in Phase 2 of Experiment 5, if the rat forgot the initial event of the terminal nonrewarded series, that series would have been indistinguishable from the terminal rewarded series, and appropriate responding under the two series would have been impossible. Apparently, the 20-pellet event, the initial event in the terminal nonrewarded series, was remembered for as long as $\mathbf{2 0} \mathrm{min}$ over a series of seven highly interfering 0-pellet events. Of course, such interference was present in each of the investigations of this report, but only in Phase 2, and possibly Phase 1, of Experiment 5 was long-delay learning also involved. In suggesting that long-delay learning can occur under conditions of extreme interference, it is not being suggested that interference is unrelated either to forgetting or long-delay learning. However, it does appear that under at least some conditions, interfer- 
ence can be overcome, and thus that its presence does not automatically preclude long-delay learning, as Lett (1979) has suggested.

Turning to Trial 1 data, neither in Phase 1 nor in Phase 2 of Experiment 5 did the rats run differentially on Trial 1 , indicating that they were unable to anticipate the first hedonic event of a series.

\section{GENERAL DISCUSSION}

The purpose of these studies was to support a novel approach to discrete-trial serial-learning tasks. According to this approach, suggested by reward schedule data and called the multiple hedonic memory view, rats can anticipate a given hedonic event in a series by remembering all prior hedonic events in the series and the order in which they occurred, even when the events are discrete, dispersed temporally, and separated by a retention interval. The findings obtained here support the multiple hedonic memory view in some detail. Furthermore, as will be shown, the capacity of alternative views to explain the present findings is limited, whatever might be the explanatory capacity of these views in other contexts or under other circumstances. We suggest, therefore, that all differential responding in this report was controlled exclusively by hedonic memory. We begin by examining alternatives to the present view.

According to a classical view of serial learning associated with Ebbinghaus (see, e.g., Crowder, 1976), the chaining view, each event in the series is the stimulus for the next. This view is clearly inadequate; it cannot explain either same or different position branching, because a given event cannot signal two different events. For the same reason, remote associations, also postulated by Ebbinghaus, cannot explain findings obtained under terminal reward series. For example, under the 0-0-20 series, the memory of 0 pellets from Trial 1 cannot simultaneously signal 0 pellets on Trial 2 and 20 pellets on Trial 3.

According to the positional cue view of serial learning (see, e.g., Crowder, 1976), distinctive cues associated with a particular trial position become associated with events on that trial. Branching behavior that occurs in the same position in two different series, for example, Trial 3 of the $0-0-20$ and $20-0-0$ series, cannot be explained by this view because a given cue cannot signal two different events. A more limited role for the positional-cue view might be suggested; it might explain, for example, slow running on 0-pellet trials that occur in the same position in both series. However, even this modest claim for the positionalcue view encounters difficulties. The positional-cue view fails to explain the series-dependent nonrewardedtrial primacy effect, why a 0-pellet trial in a given position was better anticipated in terminal nonrewarded series than in terminal rewarded series.
Haggbloom and Tillman (1980) have shown that hedonic cues are so salient that they can overshadow even brightness cues. Thus, overshadowing of positional cues, which were sometimes relevant and sometimes irrelevant, by hedonic cues, which were always fully relevant, may have occurred here, depriving the positional cues of any capacity to signal 0-pellet events. In any case, a variety of positional-cue views greatly different from that originating in human learning might also be suggested. According to such a modified view, the rat used the hedonic event on Trial 1 plus positional cues to anticipate events. Note that this hypothesis, like the present one, employs hedonic events as a basis of explanation and so invites two comments. First, if such an hedonic positionalcue view were fully developed and proved to be workable, it is difficult to say how different it would be from the present hypothesis. Second, since hedonic memory by itself might be shown to offer an entirely satisfactory explanation of the present findings, the desirability of postulating positional cues, which are not needed here, in addition to hedonic cues, which seem to be indispensible, is far from clear. Everything said above about positional cues applies to two other views-that the rats counted trials or that they employed response-produced cues.

Any attempt to explain anticipatory responding by reference to some form of stimulus change over trials that involves positional cues, counting of trials, or response-produced cues cannot ignore the differential hedonic events associated with Trial 1 of the two series. This generalization applies as well to a mechanism commonly employed in connection with many reward schedules:temporal cues. Clearly, a temporal discrimination hypothesis suggesting that the rats learned that reward would not be available for a given period following the onset of Trial 1 would be totally inadequate, since it could not explain either same position branching or the series-dependent nonrewarded-trial primacy effect. And the suggestion that the rats judged the passage of time not from Trial 1 but from the differential hedonic events on Trial 1 produces hedonic-temporal hypotheses subject to the same comments made above in connection with a hedonic positional-cue hypothesis.

Rats apparently exude different odors on rewarded and nonrewarded trials (e.g., Eslinger \& Ludvigson, 1980). Such odors, it seems, could not possibly have been an important factor here. First, runways probably retain such odors only when covered by plastic or Plexiglas, and the runway employed here was essentially open, being covered only with wire mesh. This important matter aside, such odors were followed by both reward and nonreward here and so could not have served as signals supporting differential responding. As one example, in the 0-0-20 series, the nonrewarded odor exuded on Trial 1 is followed 
by 0 pellets on Trial 2, while the nonrewarded odor exuded on Trial 2 is followed by 20 pellets on Trial 3 . As another example, considering the series employed in Experiment 4, 0-20-20 and 20-0-0, rewarded events as well as nonrewarded events were followed on the next trial by both reward and nonreward.

Another odor hypothesis is that the smell of food in the goalbox on rewarded trials and the absence of the food smell on nonrewarded trials may have led to appropriate differential responding. This view faces numerous difficulties. It cannot explain the failure to anticipate 0 pellets on Trial 1 in those series beginning with 0 pellets as employed in Experiments 1,4 , and 5 . In addition, it cannot explain either the nonrewarded trial primacy effect or the seriesdependent nonrewarded-trial primacy effect.

The present view includes two major elements. One of those has already been indicated: anticipation of each hedonic event in the series was accomplished by employing the memory of all prior hedonic events in the series and the order in which they occurred. The second major element is that stimulus generalization occurs among hedonic memories, generalizations increasing as similarity increases (see, e.g., Capaldi et al., 1980). The present interpretation may be explained initially by considering the $0-0-20$ and 20-0-0 series of Experiment 1. In those two series combined, one memory signaled reward while three memories signaled nonreward. Under the $0-0-20$ series, $\mathrm{S}^{0}$, the memory of a single 0 -pellet event, signaled 0 pellets (written as $S^{0} \rightarrow 0$ ), while the memory of two 0 -pellet events, $S^{0}+S^{0}$, signaled 20 pellets $\left(S^{0}+S^{0} \rightarrow 20\right)$. Similarly, under the $20-0-0$ series, $S^{20} \rightarrow 0$ on Trial 2 and $S^{20}+S^{0} \rightarrow 0$ on Trial 3. In Experiment 1, then, one memory was a signal for reward, $S^{0}+S^{0}$, while three memories were signals for nonreward, $S^{0}, S^{20}+S^{0}$, and $S^{20}$, these being listed in order of decreasing similarity from $S^{0}+S^{0}$. It is perhaps obvious why $S^{0}+S^{0}$, the memory of two nonrewarded events, is more similar to $S^{0}$, the memory of a single nonrewarded event, than to $S^{20}$, the memory of a rewarded event, and thus why $S^{20}+S^{0}$ is of intermediate similarity to $\mathrm{S}^{0}+\mathrm{S}^{\mathrm{o}}$.

It is suggested that the capacity to signal reward generalizes, that such generalization increases as similarity increases, and that the greater the generalized reward signal capacity received by a memory, the more difficult it will be for that memory to become a signal for nonreward. According to this view, anticipatory responding here was to a considerable extent a similarity-generalization-controlled phenomenon. Thus, as found in Experiment 1, anticipatory responding should have occurred to $\mathrm{S}^{20}$, the memory least similar to $S^{0}+S^{0}$, before it occurred to $S^{20}+S^{0}$, which explains the nonrewarded-trial primacy effect (20-0-0 series). And it should have occurred to $S^{20}$ before it occurred to $S^{0}$, which explains the seriesdependent nonrewarded-trial primacy effect.
These principles explain the nonrewarded-trial serial-position effect not merely in Experiment 1, but in all cases in which both series were of the intervening nonrewarded type in this report. In all such series employed here, the earlier an event in either series, the more dissimilar was its memory from that signaling reward, and at any given position in the two series such dissimilarity was greater in the terminal nonrewarded series than in the terminal rewarded series, because the former series contained $\mathrm{S}^{20}$, a memory not present in terminal rewarded series. In Experiment 5 , for example, $S^{0}+S^{0}+S^{0}+S^{0}$ signaled reward. Similarity to $S^{0}+S^{0}+S^{0}+S^{0}$ clearly increased progressively over the terminal rewarded series considering the memories produced by the first event $\left(S^{0} \rightarrow 0\right)$, the second event $\left(S^{0}+S^{0} \rightarrow 0\right)$, and the third event $\left(S^{0}+S^{0}+S^{0} \rightarrow 0\right)$. This is true in the terminal nonrewarded series as well, in which there was the progression $S^{20} \rightarrow 0, S^{20}+S^{0} \rightarrow 0, S^{20}+S^{0}+S^{0} \rightarrow 0$, and $S^{20}+S^{0}+S^{0}+S^{0} \rightarrow 0$. And $S^{0}+S^{0}+S^{0}+S^{0}$ is clearly more similar to the memory of the first event in the terminal rewarded series, $S_{0}$, than to the memory of the first event in the terminal nonrewarded series, $\mathrm{S}^{20}$, and so on. The principles also explain responding under the 1-0-20 and 20-0-0 series of Experiment 2 and the 5-0-20 and 20-0-0 series of Experiment 3, as the reader may determine. Importantly, they explain why it was so easy for the rats to anticipate the newly added 0-pellet trials in Phase 2 of Experiment 5 beyond the first of such additional trials. This is because the memories associated with the second, third, and fourth newly added 0-pellet trials in Phase 2 became progressively dissimilar to the memory signaling reward, $S^{0}+S^{0}+S^{0}+S^{0}$. More generally, we may say that as the terminal nonrewarded series becomes increasingly longer than the terminal rewarded series generalization decrement begins to increase again. For example, the memory of four 0-pellet events, which signaled reward in Experiment 5, is more similar to $S^{20}$ plus the memory of four 0-pellet events, which signaled 0 pellets on Trial 6 of the terminal nonrewarded series, than it is to $S^{20}$ plus the memory of seven 0 pellet events, which signaled 0 pellets on Trial 9 of the terminal nonrewarded series. In sum, as the terminal nonrewarded series departs from the terminal rewarded series in being either shorter or longer, generalization decrement progressively increases and anticipatory responding should become progressively easier.

Experiment 4 employed the series 0-20-20 and 20-0-0. On the basis of the principles outlined above, the absence of a nonrewarded-trial primacy effect in the 20-0-0 series in Experiment 4 is completely understandable. Note first that Group 0-20-20 of Experiment 4 is the only group in this report in which two memories rather than only one signaled reward. The memories signaling reward were $\mathrm{S}^{0}$ and $\mathrm{S}^{0}+\mathrm{S}^{20}$. It seems clear that in Group 0-20-20 the two memories 
which signaled 20 pellets, $S^{0}$ and $S^{0}+S^{20}$, supplied the two memories which signaled 0 pellets, $S^{20}$ and $\mathrm{S}^{20}+\mathrm{S}^{0}$, with very considerable and about equal capacity to signal reward, thereby precluding a nonrewarded-trial primacy effect.

One further implication of our view is that once the rat learns the series, as described above, the individual elements may be forged into a single unit, or whole, such that given the first event of the series all subsequent events may be anticipated. Surely, if rats can remember having received multiple events, as demonstrated in this report, there is no reason, in principle, why they cannot anticipate, not merely the next event, but two or more events in temporal series.

In partial reinforcement investigations, the rat's capacity to remember how many nonrewarded trials it has received has been investigated employing a variable called N-length (see, e.g., Capaldi, 1964). $\mathrm{N}$-length refers to the number of nonrewarded trials which precede a rewarded trial in a schedule of partial reinforcement. If a single nonrewarded trial precedes a rewarded trial, N-length is 1 , if two nonrewarded trials precede a rewarded trial, N-length is 2 , and so on. It was hypothesized that if $\mathrm{N}$-length is 1 , rats learn that $S^{0}$ signals reward; if it is 2 , rats learn that $\mathrm{S}^{0}+\mathrm{S}^{0}$ signals reward, and so on. Support for this view is provided by extinction investigations. That is, it has been found that as $\mathrm{N}$-length increases so too does subsequent resistance to extinction (e.g., Capaldi, 1964). The reason for this, it has been suggested, is that the memories associated with the longer $\mathrm{N}$-length become signals for reward and so provide considerable reward-signal capacity to the similar memories of nonreward associated with the later trials of extinction, thereby increasing vigor of responding later in extinction. Extinction findings of this sort, while clearly consistent with the notion that rats can remember more than one nonrewarded event, do so indirectly as a result of an inference chain. Moreover, efforts to supply more direct evidence that rats can remember how many nonrewarded events they have received have been frustrated in one way or another (see, e.g., Bloom \& Capaldi, 1961; Capaldi, 1979). However, direct evidence of this was supplied in this report. That is, in the terminal rewarded series employed here which contained more than one 0pellet trial, the 0-0-20 series of Experiment 1 and the 0-0-0-0-20 series of Experiment 5, rats responded appropriately, running more slowly on all intervening 0-pellet trials than on the terminal rewarded trial, indicating, unmistakably it would seem, that they were capable of determining exactly how many nonrewarded trials precede a rewarded trial. In addition, the tracking of the terminal 20-pellet event in the 0-0-0-0-20 series of Experiment 5 was highly accurate; the rats ran as rapidly on the terminal rewarded trial as on Trial 1 of the series, or about as fast as rats are able to run. Thus, it would be hard to imagine a more direct demonstration of the effects of the $\mathrm{N}$ length variable than was evidenced in connection with the terminal rewarded series of Experiment 1, and particularly of Experiment 5, in which the rat had to, and did, learn and remember that four nonrewarded events preceded a rewarded event. We may conclude, therefore, that the rat's capacity to determine and remember how many nonrewarded events it has received is highly accurate, so much so as to suggest some form of counting mechanism.

Turning to another matter, the investigations reported here indicate that rats can employ multiple hedonic memory, but not that they necessarily always do so. That is, in order to master the branching series used in these studies, the use of multiple hedonic memory was necessary, something which is not required, of course, with all series. The question that arises is: Do rats employ multiple hedonic memory in connection with all series, even if it is not necessary, or do they employ multiple hedonic memory only when it is required, when other solutions fail? Whatever may ultimately be revealed, it is clear that neither approach is without its advantages or its difficulties. A major advantage in employing multiple hedonic memory with all series is that no matter how a hedonic series may be constructed, it can be learned by employing multiple hedonic memory. This, of course, is not always the case when only some subset of prior events is remembered, such as adjacent events. Another potential advantage of multiple hedonic memory is that it may aid in forging events of a series into a whole, such that when the first event occurs all subsequent events are anticipated.

But the use of multiple hedonic memory also has costs. One such cost is that it places a heavy strain on memory. More importantly, however, it can generate considerable interference, a point raised in connection with Phase 2 of Experiment 5. Such interference will convert a relatively easy serial learning task into a difficult one. For example, consider a series of three highly dissimilar events, A-B-C. Such a series can be mastered by employing adjacent hedonic memories $(A \rightarrow B$ and $B \rightarrow C)$. It can also be mastered be employing multiple hedonic memories $(A \rightarrow B$ and $A+B \rightarrow C)$. It is clear that the use of multiple hedonic memory generates more interference than does adjacent memory, because when multiple hedonic memory is employed $A$ not only signals $B$, but is also a part of a stimulus complex, $\mathrm{A}+\mathrm{B}$, signaling an entirely different event, $C$. And the longer the series, the greater the problem of interference becomes. Thus, we see that, because multiple hedonic memory can be used to master any series, it would make sense to employ it under all conditions, thereby avoiding the possibility of inappropriate solutions 
and false starts. However, because of interference, it would make sense to employ multiple hedonic memory only as a last resort, after simpler solutions had failed.

\section{REFERENCES}

Bloom, J. M., \& CAPaldi, E. J. The behavior of rats in relation to complex patterns of partial reinforcement. Journal of Comparative and Physiological Psychology, 1961, 54, 261-265.

Capaldi, E. J. Effect of N-length, number of different $\mathbf{N}$-lengths and number of reinforcements on resistance to extinction. Journal of Experimental Psychology, 1964, 63, 230-239.

Capaldi, E. J. Partial reinforcement: A hypothesis of sequential effects. Psychological Review, 1966, 73, 459-477.

Capaldi, E. J. A sequential hypothesis of instrumental learning. In K. W. Spence \& J. T. Spence (Eds.), The psychology of learning and motivation (Vol. 1). New York: Academic Press, 1967.

CaPaldi, E. J. Latent discrimination learning under a regular schedule of partial reinforcement. Animal Learning \& Behavior, $1979,7,63-68$.

Capaldi, E. J., Berg, R., \& Mornis, M. D. Stimulus control of responding in the early trials of differential conditioning. Learning and Motivation, 1975, 6, 217-229.

Capaldi, E. J., \& LYNCH, D. Patterning at a 24-hour ITI: Resolution of a discrepancy more apparent than real. Psychonomic Science, 1966, 6, 229-230.

Capaldi, E. J., Verry, D. R., \& Davidson, T. L. Memory, serial anticipation pattern learning, and transfer in rats. Animal Learning \& Behavior, 1980, 8, 575-585.

Crowder, R. G. Principles of learning and memory. Hillsdale, N.J: Erlbaum, 1976.

Devine, J. V., Burke, M. W., \& Rohack, J. J. Stimulus similarity and order as factors in visual short term memory in nonhuman primates. Journal of Experimental Psychology: Animal Behavior Processes, 1979, 5, 335-354.
Eslinger, P. J., \& Ludvigson, H. W. Are there constraints on learned responses to odors from rewarded and nonrewarded rats? Animal Learning \& Behavior, 1980, 8, 452-456.

Hagabloom, S. J., \& Tillman, D. J. Sequential effects on discrimination reversal. Learning and Motivation, 1980, 11, 318-338.

Honio, W. K. Studies of working memory in the pigeon. In S. H. Hulse, H. Fowler, \& W. K. Honig (Eds.), Cognitive processes in animal behavior. Hillsdale, N.J: Erlbaum, 1978.

Hulse, S. H. Cognitive structure and serial pattern learning by rats. In S. H. Hulse, H. Fowler, \& W. K. Honig (Eds.), Cognitive processes in animal behavior. Hillsdale, N.J: Erlbaum, 1978.

HUNTER, W. S. The temporal maze and kinaesthetic sensory processes in the white rat. Psychobiology, 1920, 2, 1-18.

Jobe, J. B., Melloren, R. L., Feinberg, R. A., Litrlejohn, R. L., \& Riaby, R. L. Patterning, partial reinforcement and $\mathbf{N}$-length effects at spaced trials as a function of reinstatement of retrieval cues. Learning and Motivation, 1977, 8, 77-97.

LETT, B. T. Long delay learning in the T-maze. Learning and Motivation, 1975, 6, 80-90.

LETT, B. T. Long delay learning: Implications for learning and memory theory. In N. S. Sutherland (Ed.), Tutorial essays in experimental psychology (Vol. 2). Hillsdale, N.J: Erlbaum, 1979.

MAK1, W. S., \& HegviK, D. K. Directed forgetting in pigeons. Animal Learning \& Behavior, 1980, 8, 567-574.

Restle, F., \& Brown, E. Organization of serial pattern learning. In G. Bower (Ed.), The psychology of learning and motivation (Vol. 4). New York: Academic Press, 1970.

Schlogezro, H., \& KATz, A. Double alternation level pressing in the white rat. American Journal of Psychology, 1943, 56, 274282.

Sнiмp, C. P. Short-term memory in the pigeon. Journal of the Experimental Analysis of Behavior, 1976, 25, 55-61.

(Manuscript received April 20, 1981; revision accepted for publication August 21, 1981.) 